\title{
DIGNIDADE HUMANA E INCLUSÃO SOCIAL NAS RELAÇÕES DE TRABALHO
}

\author{
Sandra Morais de Brito Costa ${ }^{*}$ \\ Beatriz Cardoso Montanhana*
}

\section{Resumo}

$\mathrm{O}$ artigo, baseado em método dedutivo de análise, trata da relevância do permanente olhar sobre a dignidade humana como fundamento das relações socioeconômicas e jurídicas, entre elas as de trabalho. O primado da dignidade humana repousa na inclusão social, pautada nos direitos fundamentais de trabalhadores. A Constituição visa à superação da exclusão social. Daí decorre a responsabilidade das empresas pela inclusão social e dignidade no trabalho. A dignidade perpassa as referências da sociedade (econômicas, políticas, jurídicas, sociais), e a importância da eficiência das decisões judiciais, com análise de suas consequências, é um dos aspectos relevantes para a garantia dos direitos sociais.

Palavras-chave: Dignidade. Inclusão. Igualdade. Trabalho. Consequencialismo.

\section{HUMAN DIGNITY AND SOCIAL INCLUSION IN LABOR RELATIONS}

\begin{abstract}
This article, based on a deductive method of analysis, aims to the relevance of the permanent analysis of human dignity as the foundation of socio-economic and legal relations, including those at work. The primacy of human dignity lies on the social inclusion, according to the fundamental rights of workers. The Constitution aims to overcome social exclusion. And the responsibility of companies for social inclusion is essential for decent working relationships. Human dignity builds society's references (economic, political, legal, social). The efficiency of judicial decisions and an analysis of their consequences is one of the relevant aspects for guaranteeing social rights.
\end{abstract}

Keywords: Dignity. Inclusion. Equality. Labor. Consequentialism.

\section{INTRODUÇÃO}

O objetivo do presente artigo é descrever como a dignidade humana atua como referencial para as ações de inclusão social e de garantia do trabalho digno, a partir do método

\footnotetext{
* Mestre em Direito Político e Econômico e Especialista em Direito pela Universidade Mackenzie. Doutoranda pela Faculdade Autônoma de Direito (FADISP). Professora universitária. Auditora-Fiscal do Trabalho. Formadora institucional da Escola Nacional da Inspeção do Trabalho. Email: fbc.stjt@gmail.com http://orcid.org/0000-0003-4415-4880

* Mestre e Doutora pela Faculdade de Direito/USP. Professora universitária. Auditora-Fiscal do Trabalho. Formadora institucional da Escola Nacional da Inspeção do Trabalho. Email: beatriz.montanhana@alumni.usp.br https://orcid.org/0000-0003-0845-3816
} 
dedutivo com pesquisa bibliográfica. Sua justificativa repousa na permanente necessidade de afirmar a centralidade dos direitos humanos como parâmetro para o modelo de constituição da sociedade brasileira. Isso implica relações socioeconômicas e jurídicas pautadas na garantia da dignidade humana, a exemplo das relações de trabalho.

Para tanto, inicialmente, faz-se necessário compor as matrizes principiológicas, especialmente a igualdade, seguindo o curso do método sistemático para estudo do tema. Destaca-se que o sistema constitucional de proteção a pessoa humana começa pelo princípio da igualdade, qualificado por Luiz Alberto David Araújo (1996, p. 98) como "patrimônio jurídico", que corresponde ao cumprimento do direito à igualdade, cuidando de resguardar a obediência à isonomia de todos diante do texto legal, evitando discriminações e estabelecendo ações afirmativas perfeitamente justificadas e explicadas pela própria dificuldade de integração natural de diversos grupos de pessoas.

Passa-se, então, à análise da importância da constitucionalização dos direitos sociais como mecanismo jurídico para materialização da dignidade humana, que, sem negar o valor transcendente e moral, demanda uma práxis, ou seja, uma ação social transformadora. Ao reconhecer os direitos sociais, a sociedade constitucionalmente atua em nome na ruptura da superação do fenômeno intergeracional, que é a exclusão social.

A construção de todo arcabouço de proteção social ampara-se no primado da dignidade humana. Assim, o artigo tem por premissa estabelecer como parâmetro para qualquer inclusão social, com destaque para a inclusão de pessoas com deficiência no mercado de trabalho, a promoção da dignidade humana, em seu conceito multidimensional: social, político, econômico e jurídico.

$\mathrm{Na}$ medida em que a inclusão social de pessoas com deficiência no mercado de trabalho passa por políticas de cota, envereda-se ainda por uma outra seara: a responsabilidade social dos particulares. Reforça-se aqui a importância de discutir e analisar a dignidade da pessoa humana como um construto de uma sociedade como um todo, ou seja, como fundamento de uma Constituição. Nessa abordagem, é relevante considerar o princípio da liberdade, referenciado pela dignidade humana.

O objetivo é compreender que todo o ordenamento jurídico se modela a partir do padrão de referência pautado pela dignidade humana, incorporando para tanto mecanismos de promoção de condutas de inclusão social. Nesse diapasão, o estudo propõe apresentar questões relacionadas à responsabilidade objetiva das empresas na promoção da inclusão 
social e o papel do judiciário sob a ótica consequencialista, a fim de assegurar, por meio de suas decisões, a eficácia do direito ao trabalho digno.

Esclarece-se que, durante todo o estudo, o trabalho será contextualizado como o é em nosso ordenamento jurídico: um direito fundamental intrínseco ao exercício pleno da cidadania.

\section{DIGNIDADE HUMANA NAS RELAÇÕES DE TRABALHO}

O conteúdo jurídico do princípio da igualdade é dúplice: igualdade formal ou perante a lei, e igualdade material ou igualdade na lei. A igualdade formal está consagrada no caput, do art. $5^{\circ}$, da Constituição da República, verbis:

Art. $5^{\circ}$ Todos são iguais perante a lei, sem distinção de qualquer natureza, garantindo-se aos brasileiros e aos estrangeiros residentes no País a inviolabilidade do direito à vida, à liberdade, à igualdade, à segurança e à propriedade[...]

O constituinte de 1988 , quando inseriu a igualdade no caput do art. $5^{\circ}$, erigiu-a à condição de princípio, pressuposto de entendimento dos direitos individuais. Luiz Alberto David Araújo, observa que a igualdade não foi fixada apenas como um dispositivo, mas passou a constar como regra matriz. A propósito, comenta Celso Ribeiro Bastos (1998, p. 13):

$\mathrm{O}$ atual artigo isonômico teve trasladada a sua topografia. Deixou de ser um direito individual, tratado tecnicamente como os demais. Passou a encabeçar a lista destes direitos, que foram transformados em parágrafos do artigo igualizador.

Essa transformação é prenhe de significado. Com efeito, reconheceu-se à igualdade o papel que ela cumpre na ordem jurídica. Na verdade, a sua função é um verdadeiro princípio a informar e condicionar todo o restante do direito. É como dizer: assegura-se o direito de liberdade de expressão do pensamento, respeitada a igualdade de todos perante este direito.

Portanto, a igualdade não assegura nenhuma situação jurídica específica, mas protege o indivíduo contra qualquer má utilização que se pode fazer da ordem jurídica. Desse modo, todo o texto da Constituição deve ser interpretado à luz do princípio da igualdade, que atua como "regra mestra" de toda a hermenêutica constitucional e infraconstitucional. Celso 
Antônio Bandeira de Mello (2000, p. 747-748) ensina que princípio:

(...) é, por definição, mandamento nuclear de um sistema, verdadeiro alicerce dele, disposição fundamental que se irradia sobre diferentes normas, compondo seu espírito e servindo de critério para a sua exata compreensão e inteligência, exatamente por definir a lógica e a racionalidade do sistema normativo, no que lhe confere a tônica e lhe dá sentido harmônico. É o conhecimento dos princípios que preside a intelecção das diferentes partes componentes do todo unitário que há por nome sistema jurídico positivo.

Assim, como diz a doutrina, violar um princípio é muito mais grave do que transgredir uma norma qualquer. A desatenção ao princípio implica ofensa não apenas a um mandamento obrigatório específico, mas a todo o sistema de comandos. É a mais grave forma de ilegalidade ou inconstitucionalidade, conforme o escalão do princípio atingido, porque representa insurgência contra todo o sistema, subversão de seus valores fundamentais, irremissível a seu arcabouço lógico e corrosão de sua estrutura mestra.

A igualdade material ou igualdade na lei - reiterada no art. $7^{\circ}$, XXXI da Constituição da República - representa uma autorização para desigualar em busca da igualdade, diante da necessidade de conferir proteção especial aos direitos de certas pessoas ou grupos (ARAÚJO, 1996, p. 84).

Dentre as pessoas protegidas estão todas aquelas passíveis de discriminação em razão sexo, idade, cor, estado civil, deficiência, condição social, concedendo-se amparo singular, a fim de que se igualem na lei. O constituinte originário, ao conceder esta proteção especial, teve por escopo dar-lhes as mesmas condições a todas as pessoas. São regras que efetivamente discriminam, protegem, criam privilégios, isto é, vantagens essenciais para a equiparação das pessoas. São as chamadas ações afirmativas ou discriminação positiva. A igualdade material é manifestação dos princípios inspiradores dos fundamentos do Estado Brasileiro, apontados nos artigos $1^{\circ}$ e $3^{\circ}$ da Constituição Brasileira. $\mathrm{O}$ art. $3^{\circ}$ da Constituição Federal dispõe que um dos objetivos fundamentais da República Federativa do Brasil é a promoção do bem de todos, sem preconceitos de origem, raça, sexo, cor, idade e quaisquer outras formas de discriminação.

Luiz Alberto David Araújo (1996, p. 87) salienta como primordial o fato de:

A igualdade material vincular o intérprete e o legislador infraconstitucional na preservação dos valores contidos nas normas específicas de proteção constitucional. Assim, o legislador infraconstitucional da igualdade material, tratando sempre 
diferentemente, de forma privilegiada, dentro dos limites constitucionais, o grupo ou o valor protegido. O intérprete, por seu lado, não pode perder de vista a proteção de tais bens, sempre cuidando de aplicar o direito em conformidade com a proteção constitucional adotada.

Dentre os direitos fundamentais reconhecidos à toda pessoa humana está o acesso ao mercado de trabalho. A efetivação deste direito vincula-se ao princípio da igualdade no seu aspecto material, ou seja, depende que o Estado adote ações discriminatórias positivas, com o objetivo de corrigir desigualdades.

É importante ressaltar que na Adin 939-07/DF do Supremo Tribunal Federal, o Ministro Carlos Velloso considerou os direitos e garantias sociais como pertencentes à categoria dos direitos individuais, logo, imodificáveis, enquanto o Ministro Marco Aurélio afirmou a relação de continência entre os direitos sociais e os individuais, previstos no artigo $60, \S 4^{\circ} \mathrm{da} \mathrm{CF}$.

Deve-se frisar que os direitos sociais, dentre os quais o direito à inclusão a inclusão social de grupos vulneráveis, são direitos fundamentais, pois resguardam suas necessidades mais elementares.

De fato, dentre os direitos fundamentais, os direitos sociais são os que têm maior relação com as questões econômicas, tanto em nível estrutural como em nível conjuntural, e talvez por isso sejam os mais ameaçados e susceptíveis às interferências do poder econômico no País.

A constitucionalização dos direitos sociais é um processo recente, advinda de inúmeros acontecimentos históricos e fruto, principalmente, da mudança do papel do Estado, a partir de sua prestação ativa nos direitos sociais.

Nesse aspecto, a Constituição deve ser analisada sob o enfoque de sua supremacia, como lei fundamental, tanto nos direitos individuais como nos direitos econômicos e sociais. Abandonou o seu cunho simplesmente assistencial e adotou uma postura inclusiva. Ressalvamos que os direitos enumerados, exemplificativamente, no Capítulo II da CF, em especial no artigo $7^{\circ}$, não esgotam o núcleo mínimo de direitos fundamentais constitucionais.

Ressalvamos que os direitos sociais enumerados, exemplificativamente, no Capítulo II, em especial no artigo 7.o, não esgotam o núcleo de direitos mínimos existenciais do trabalhador, verdadeiros direitos fundamentais constitucionais que se encontram também difusamente previstos na própria Constituição Federal, como forma de resguardo a dignidade humana (ARRUDA, 1998, p. 19). 


\subsection{Exclusão social - faceta econômica intergeracional}

Dentre os aspectos econômicos que afrontam o princípio da dignidade da pessoa humana identificamos a persistência intergeracional de diversas fatores que impedem a concretização de nosso ideal e fundamento constitucional da erradicação da pobreza e inclusão social, dentre os quais, citamos o trabalho infantil, o racismo estrutural e a resistência injustificada de inclusão social da pessoa com deficiência.

Resultados de balizadas pesquisas retratam que o fato de os pais terem sido trabalhadores infantis apresentam um efeito positivo e significante sobre a probabilidade de seus filhos serem trabalhadores infantis, assim como as discriminações, apesar de passíveis de penalização, acabam por ser banalizadas, o que não se pode aceitar em um estado democrático de direito (AQUINO, 2010, p. 61-84).

Essas distinções sociais evidenciam a necessidade de uma maior atenção dos estudos teóricos e empíricos sobre as diferenças de contexto entre as diversas realidades que provavelmente têm determinantes diferentes, sendo também diferenciado o papel da persistência intergeracional relativo à exclusão social. Dessa forma cabe ressaltar que políticas públicas que objetivam eliminar ou reduzir a exclusão social no país e a persistência intergeracional da vulnerabilidade devem incorporar características locais intrínsecas do problema socioeconômico para obter uma maior efetividade de suas ações (AQUINO, 2010, p. 61-84). Uma postura inclusiva tem força normativa capaz de representar um fator de inserção social, eficaz na dimensão jurídica (WOLGANG, 2004, p. 20).

A constitucionalização dos direitos sociais não teve como objetivo apenas a confirmação teórica de uma proposta democrática, mas sim um programa político que implica a atuação permanente do Estado para garantir a eficácia dessas normas.

É fato, porém, que o Estado, além de sofrer limitações constitucionais sobre os direitos fundamentais, tem também a incumbência de desenvolver políticas que assegurem o exercício das liberdades individuais, de forma que tanto se subordina aos direitos fundamentais, como direitos de defesa, quanto aos direitos fundamentais, como direitos a prestações, ora assumindo postura passiva, abstendo-se de utilizar o poder, ora assumindo postura ativa, criando condições para que as liberdades individuais se mantenham (WOLGANG, 2004, p. 20). 


\section{O PRIMADO DA DIGNIDADE HUMANA}

Destaca-se, inicialmente, que segundo o texto constitucional a dignidade da pessoa humana é fundamento da República Federativa do Brasil. Conclui-se, então, que o Estado existe em função de todas as pessoas, e não estas em função do Estado. Aliás, de forma pioneira, o legislador constituinte, para reforçar a ideia anterior, colocou o capítulo dos direitos fundamentais antes da organização do Estado.

Entende-se por dignidade da pessoa a qualidade intrínseca e distintiva de cada ser humano, que o torna merecedor do mesmo respeito e consideração por parte do Estado e da comunidade, implicando, neste sentido, um complexo de direitos e deveres fundamentais que protejam a pessoa contra todo e qualquer ato degradante e desumano, garantindo as condições mínimas para uma vida saudável, propiciando e promovendo a sua participação social de forma ativa e responsável (WOLGANG, 2004, p. 20).

Assim, toda e qualquer ação do Estado deve ser avaliada, sob pena de ser inconstitucional e violar a dignidade humana, considerando cada pessoa paradigma da ação do Poder Público e um dos elementos imprescindíveis de atuação do Estado brasileiro.

A dignidade da pessoa humana, em breves linhas, deve ser vista como o direito individual protetivo (em relação ao próprio Estado ou à pessoa individualmente considerada) e como dever de receber tratamento igualitário, o que justifica um tratamento diferenciado, visando à igualdade (WOLGANG, 2004, p. 62)

Nesse diapasão afirmamos, com toda a segurança, que outros princípios consagrados e expressos na Constituição somente tomam força e se coadunam harmoniosamente se for considerada a tríplice característica da democracia: representação, participação e respeito aos direitos e garantias fundamentais, desde que alinhavados sob a ótica da dignidade humana.

Como se vê, a dignidade humana, além de ser o fundamento do Estado Democrático de Direito, orienta o operador do Direito nos diversos ramos das ciências jurídicas, visando cumprir um papel transformador, mormente pela busca de uma sociedade justa.

A dignidade perfaz o conteúdo mínimo dos direitos humanos fundamentais. Assim, ela é o núcleo fundamental de todos os direitos. Isto significa que seu sacrifício importa na violação ao valor essencial da pessoa humana.

Ao reconhecer a íntima vinculação entre a dignidade humana e os direitos fundamentais, percebemos dois aspectos fundamentais: uma ação negativa (passiva), por parte 
do Estado, para evitar agressões; e uma ação positiva (ativa), para promover ações concretas que criem condições efetivas de uma vida digna para todos, como preconiza uma concepção constitucional inclusiva.

Depreende-se do posicionamento de Maria Celina Bodin de Moraes os quatro corolários do princípio da dignidade humana: igualdade, liberdade, integridade psicofísica e solidariedade. Nesse ponto, cabe apontarmos, de forma breve, alguns aspectos da igualdade como alicerce da dignidade humana, a fim de demonstrar a pertinência lógica da discriminação positiva relativa a situações sociais que impliquem vulnerabilidades sociais estruturais (MORAES, 2003, p. 92).

A vulnerabilidade social é o conceito que caracteriza a condição dos grupos de indivíduos que estão à beira da sociedade, ou seja, pessoas ou famílias que estão em processo de exclusão social, principalmente por fatores socioeconômicos (MARGUTI; SANTOS, 2019).

No Brasil o Índice de Vulnerabilidade Social (IVS), exibe esta avaliação baseando-se em dados do Censo Demográfico produzidos pelo IBGE.

Esse índice representa a condição de vulnerabilidade utilizando a média de três dimensões:

- Infraestrutura urbana: nesse caso, são utilizados dados como o abastecimento de água, rede de esgoto sanitário e coleta de lixo;

- Capital humano: acesso à educação e condições de saúde;

- Renda e trabalho: considera a insuficiência de renda das famílias, a desocupação de adultos ou ocupação informal sem ensino fundamental, dependência da renda de pessoas idosas e presença de trabalho infantil (MARGUTI; SANTOS, 2019).

Quanto mais alto o IVS em determinado território, maior a precariedade das condições de vida da população, resultando em um IVS com valores próximos a um (pior situação), enquanto valores próximos a zero indicam baixa, ou inexistente, vulnerabilidade.

Considerando esse índice e utilizando os dados do Censo de 2010, o Brasil era, em 2000, um país de alta vulnerabilidade social. Passados dez anos, observou-se uma queda de $26,9 \%$ no índice. Nesse período, o Brasil passou para a faixa média de vulnerabilidade social (de 0,446 para 0,326$)$.

O Atlas da Vulnerabilidade Social exibe os respectivos Índices de Vulnerabilidade Social para cada local, permitindo a visualização imediata da desigualdade de condições de 
vida presentes nas diversas escalas do território brasileiro (COSTA, M. A.; MARGUTI, B. O., 2015).

Ao longo da história da política brasileira sempre esteve presente a questão da desigualdade social. Principalmente a partir da Constituição de 1988, foram criados programas de proteção social para mitigar a situação de vulnerabilidade que alcançava grande parte da população.

\subsection{Igualdade material}

A insuficiência reconhecida da igualdade formal levou o legislador constituinte a adotar, paralelamente a essa, como princípio fundamental, a igualdade substancial, consagrada no art. 3.o, inc. III do texto constitucional. Tratar igualmente os iguais e desigualmente os desiguais, suprindo as carências físicas, intelectuais, econômicas ou sociais dos menos favorecidos, oferecer igualdade de oportunidades é o caminho para a obtenção da igualdade substancial (RAMOS, 2006, p. 5).

Permitir que a igualdade formal e o mercado regulem tais relações seria um caminho, isto sim, para aumentar o poder do mais forte sobre o mais fraco. Registre-se que, atualmente, mais que o direito à igualdade, surge como fundamental o direito à diferença. A igualdade material sugere o reconhecimento das diferenças, ou seja, a garantia às minorias de se manifestarem livremente, sem a necessidade de adotar comportamentos uniformizantes que os descaracterizem como tal (SANTOS, 2002, p. 27).

Certamente as pessoas e os grupos sociais têm o direito de ser iguais quando a diferença os inferioriza, e o direito a ser diferentes quando a igualdade os descaracteriza.

Cumpre, nesse aspecto, destacarmos de que a proteção das pessoas em situação de vulnerabilidade é um modo de preservar a cidadania e a dignidade da pessoa humana, extinguindo as desigualdades sociais (ARAÚJO, 1996, p. 81).

$\mathrm{O}$ acesso ao mercado de trabalho, direito humano fundamental, pois tem valor existencial de enorme relevância, já que só por meio do trabalho é possível prover a si e a sua família.

Frise-se que os direitos humanos são fundamentais a todas as pessoas, e a inserção no mercado de trabalho, faz com que todos vivam mais e melhor. 


\subsection{Trabalho como fundamento de dignidade humana}

Assim, a justificativa máxima e filosófica do direito do trabalho é a dignidade humana e os direitos fundamentais dos trabalhadores como seres humanos. Por isso, a Declaração de Filadélfia, integrante da Constituição da Organização Internacional do Trabalho - OIT, da qual o Brasil é membro fundador, diz expressamente que o trabalho não é mercadoria. Ele não pode ser negociado por ninguém, somente pelo próprio trabalhador, segundo regras emanadas do Estado ou advindas da autonomia coletiva da vontade dos grupos sociais, e naquilo que não prejudicar o trabalhador.

Saliente-se que dentre as atividades humanas fundamentais destaca-se o labor como a atividade relacionada diretamente com a própria vida - assegura a sobrevivência do indivíduo e a vida da espécie, garantindo a sua dignidade (ARENDT, 1981, p. 57).

Sem dúvida, o trabalho é um direito social fundamental e a sua reivindicação é essencial - tão fundamental que passou a fazer parte de todas as declarações de direito contemporâneas - e teve as mesmas boas razões da reivindicação ao direito de propriedade como direito natural (BOBBIO, 2004, p. 71).

Observe-se que a Declaração de Direitos do Homem e do Cidadão, em seu artigo 23.1, indica o trabalho como direito fundamental, ao dispor que: "Todo homem tem direito ao trabalho, à livre escolha do emprego, a condições justas e favoráveis de trabalho e à proteção contra o desemprego".

Trata-se de um direito materialmente fundamental, contudo, as diferenças entre os indivíduos têm sido utilizadas como fator de limitação e até de supressão do direito ao trabalho.

Portanto, o direito ao trabalho constitui-se em direito da pessoa humana, e, significa a faculdade que cada homem tem de exercer uma atividade útil para si, sua família e a sociedade, mediante uma justa remuneração. Certamente esse direito implica uma política social capaz de proporcionar uma estrutura e uma organização ricas em oportunidades para que os indivíduos possam usufruir de uma boa aprendizagem e uma adequada formação profissional (MORAES FILHO, 1975, p. 39).

$\mathrm{Na}$ verdade, enquanto a declaração do direito ao trabalho, nacional ou internacional, não se transformar num direito público subjetivo, como pretensão jurídica, cujo titular possa exigir o seu cumprimento por quem de direito (Estado ou particular) não passará de um belo 
preceito moral ou jurídico, simplesmente programático.

De fato, cumpre reconhecer que no campo dos direitos do homem - ou, mais precisamente, das normas que declaram, reconhecem, definem e atribuem direitos aos homens - aparece, certamente, o direito ao trabalho, como aquele em que a defasagem entre a posição da norma e sua efetiva aplicação é maior (BOBBIO, 2004, p. 77).

Por certo a negação ao trabalho manifesta-se em uma estrutura socioeconômica da qual decorrem o subemprego e o desemprego. Assim, o Estado pode e deve intervir para o resgate de sua dignidade e cidadania, utilizando o direito ao trabalho como um instrumento de inclusão social, balizando direitos e garantias individuais.

\section{RESPONSABILIDADE DAS EMPRESAS NA GARANTIA DE RELAÇÕES DIGNAS DE TRABALHO}

Conforme exposto, a dignidade humana, como fundamento constitucional, é pilar para a promoção de inclusão social. Os dados de vulnerabilidade social e a construção contínua de modelos normativos de garantia de igualdade material são os elementos fático e jurídico, respectivamente, que constituem fenômenos a serem analisados e valorados constantemente pela sociedade constitucionalmente organizada. Ou seja, a sociedade deve continuamente se debruçar sobre os fatos, identificar os bens juridicamente relevantes para a promoção da inclusão social e determinar quais valores estão envolvidos ${ }^{1}$.

\footnotetext{
${ }^{1}$ Parte-se da construção teórica do jurista Miguel Reale, na clássica obra "Teoria Tridimensional do Direito" ( $5^{\mathrm{a}}$ ed. São Paulo: Saraiva, 1994). Como destaca o próprio autor no Prefácio à $2^{\mathrm{a}}$ edição, consiste na elaboração de tese que analisa o "Direito como experiência", com a "aspiração no sentido de harmonizar a lógica das regras jurídicas com as exigências reais da vida social” (p. XIV).
} 
Sob esse contexto, entende-se que, sob o ponto de vista jurídico, a concepção da dignidade humana é um construto social, não um dado a priori. Esse viés de compreensão conduz para um diálogo sobre o significado da dignidade humana, a partir de fatos, normas e valores identificados em um ambiente complexo. E a complexidade evidencia-se ainda mais quando as relações estabelecidas são de natureza trabalhista.

A dignidade humana na esfera das relações de trabalho depende essencialmente da garantia de um direito: direito ao trabalho. Esse direito não depende tão-somente da atuação do Estado, mas de um compromisso assumido por toda a sociedade. O direito ao trabalho digno surgiu no curso do processo constante e inacabável de reconhecimento dos Direitos Humanos. Em especial, o atual período histórico clama por uma maior atenção no que se refere ao direito ao trabalho, pois as transformações econômico-políticas e sociais vêm expondo um dilema: a de que o trabalho não seja mais um elemento essencial para a produção da riqueza humana e se torne um bem cada vez mais escasso. A crescente automação do processo produtivo é um dos fatores a corroborar esse cenário.

Por ora, a importância do trabalho é indiscutível. quando ainda é constatada a presente dependência da mão de obra para a consecução de atividades econômicas. E o trabalho segue como fonte de sobrevivência da maior parcela da humanidade, que, portanto, não pode ser privada desse direito. A conscientização desse compromisso social faz-se necessária.

Exsurge, então, a abordagem do trabalho com dignidade como uma ação necessária para o equilíbrio e harmonia da sociedade, daí a busca por proteção ao trabalho e ao trabalhador, por pleno emprego, por redução de desigualdades, por não discriminação no trabalho, por proteção contra a automação e outros princípios e valores contemplados em Constituições, como a brasileira promulgada em 1988. Trabalhar é um agir que vai muito além do olhar estritamente econômico ou social ou político ou histórico etc. Isto é, ele compreende uma análise complexa de sistemas que compõem uma sociedade constituída sob o fundamento da dignidade humana, como é a brasileira.

Se essa abordagem pode parecer óbvia nos dias de hoje - até porque decorre de previsões da própria Constituição Brasileira -, ela não orientava a lógica de produção de bens e serviços pautada na utilização ou exploração da mão de obra. Exemplo disso é a questão da inclusão de pessoa com deficiência no mercado de trabalho. A doutrina cristã, na Idade Média, atribuiu aos doentes e pessoas com deficiência a marca dos pauper Christi (pobres de 
Cristo). O estigma do sofrimento e da pobreza os exonerou da obrigação de trabalhar, e estabeleceu ao mesmo tempo a percepção discriminatória de que o pauper Christi merecia ser assistido (CASTEL, 2003, p. 22-23).

A tônica da inclusão social nas relações de trabalho está na modelagem de instrumentos jurídicos que determinam condutas a serem adotadas pelos seus destinatários, quais sejam os empregadores. Exemplos de ações que visam à inclusão social nas relações de trabalho são as políticas de cota de pessoas com deficiência ou reabilitadas ou de aprendiz.

Por essa razão, em regra, o que se conclui é que as políticas de inclusão social por meio do acesso ao trabalho resultam em ações de combate à discriminação. E esse é mais um desafio: romper com o paradigma de discriminação, que passa por um discurso de reconhecimento do direito ao trabalho digno amplo e irrestrito, em uma sociedade marcada pela diversidade. Isto é, as políticas públicas devem ser pensadas e estar voltadas ao estímulo de condutas para inclusão social. Da mesma forma, as normas jurídicas devem ser elaboradas e aplicadas para estimular condutas, para incentivar o comportamento.

Grandes empresas e multinacionais em atividade no país adotam políticas de responsabilidade social corporativa, seguindo a lógica de que não se enquadra nos moldes de responsabilização jurídica. Contudo, a responsabilidade social corporativa (RSC) tem contornos jurídicos, na medida em que são traduções do reconhecimento do impacto das atividades econômicas pelas próprias empresas, as quais implicam a sua responsabilidade trabalhista como beneficiárias diretas do produto da exploração da mão de obra.

Luís Antonio Camargo de Melo et al (2015, p. 318-319) trazem o exemplo do impacto da utilização da mão de obra em cadeias de valor no setor das confecções:

O Governo do Brasil, subsidiado pelo MPT, demonstrou matematicamente que no setor de confecções, em que é comum trabalho em jornadas exaustivas (das $7 \mathrm{~h}$ à meia noite, de segunda a sábado), sem oficialização de vínculo de emprego, sem direito de férias, com remuneração mensal de US\$ $150,00 / 200,00$ por mês, o proprietário da oficina e a confecção que a contrata auferem uma vantagem mensal de ao menos US\$1.000,00. Em uma oficina com vinte trabalhadores assim explorados, é como se houvesse uma vantagem competitiva mensal de US\$20.000,00 em relação ao empresário cumpridor da legislação, inviabilizando a competição leal.

O impacto econômico é inquestionável, inclusive afetando diretamente o direito à livre concorrência. Como destaca o autor, a situação não "se resume" à tutela do trabalhador 
encontrado, nesse caso, em condições análogas às de escravo, mas à proteção de todo um setor econômico envolvido: "os interesses de empregadores cumpridores da legislação e o interesse de todos os demais trabalhadores na iminência de despojamento de direitos em decorrência do nivelamento por baixo das práticas concorrenciais” (MELO et al, 2015, p. $319)$.

Disso resulta a importância da teoria da responsabilidade jurídica objetiva, como instrumento de estímulo de conduta e incentivador de boas práticas. Nas hipóteses de aparente ausência de culpa/dolo ou de despersonificação dos agentes causadores de danos, principalmente para proteção de Direitos Fundamentais (a exemplo do Direito Ambiental), a teoria da responsabilidade estimula a promoção de medidas de internalização das externalidades negativas.

Nesse contexto, vale mencionar que o Supremo Tribunal Federal aprovou o Tema n. 932, que versa sobre a possibilidade de responsabilização objetiva do empregador por danos decorrentes de acidentes de trabalho, a partir da aplicação de preceito geral previsto no Código Civil:

O artigo 927, parágrafo único, do Código Civil é compatível com o artigo $7^{\circ}$, XXVIII, da Constituição Federal, sendo constitucional a responsabilização objetiva do empregador por danos decorrentes de acidentes de trabalho, nos casos especificados em lei, ou quando a atividade normalmente desenvolvida, por sua natureza, apresentar exposição habitual a risco especial, com potencialidade lesiva e implicar ao trabalhador ônus maior do que aos demais membros da coletividade.

O Direito do Trabalho é um direito de contratos. A alegação de ausência de culpa ou de conhecimento das condutas contrárias aos direitos fundamentais não encontra amparo legal, ensejando o exercício do devido cuidado com as condições em que a mão de obra será explorada, desde a elaboração dos termos de contratação pelas empresas até a execução final do contrato, seja ela de natureza civil, empresarial ou comercial. Trata-se da aplicação de princípios basilares na teoria geral dos contratos, merecendo destaque a boa-fé objetiva ${ }^{2}$ e a

\footnotetext{
${ }^{2} \mathrm{O}$ princípio da boa-fé objetiva decorre uma cláusula geral de deveres anexos ao contrato, a ser moldada de acordo com as circunstâncias contratuais. TEPEDINO e SCHREIBER exemplificam: "Enquanto no contrato de compra e venda de um automóvel exige-se que o vendedor forneça ao comprador toda informação relevante acerca do veículo e qualquer outro dado relacionado à função social e econômica do contrato, a aquisição de controle de uma determinada sociedade, por outro lado,
} 
função social dos contratos ${ }^{3}$.

Torna-se necessária a revisão de conceitos sob a ótica das novas formas de trabalho. Essa revisão de conceitos, a partir da recepção e integração pelo sistema jurídico das novas formas de trabalho, está refletida em decisões já proferidas em tribunais de outros países que reconhecem, por exemplo, o vínculo empregatício de trabalhadores em plataformas digitais (SATARIANO, 2021).

Enfim, impõe-se que a sociedade constitucionalmente organizada supere as suas aparentes contradições jurídicas, a exemplo da aparente dicotomia entre livre concorrência e função social dos contratos. Para tanto, torna-se, assim, imprescindível o reconhecimento da responsabilidade social corporativa como responsabilidade jurídica, face aos bens e valores envolvidos, reconhecidos pelo ordenamento jurídico. Ou seja, a juridicidade da responsabilidade trabalhista pelas corporações decorre do próprio ordenamento jurídico, desde previsão em normas constitucionais até as infralegais.

Diante do exposto, não é possível deixar de analisar a importância das decisões judiciais, como incentivadoras de conduta, nas ações cujo objeto seja a garantia da dignidade humana dos trabalhadores por meio do reconhecimento da responsabilidade objetiva de empresas.

\subsection{A dignidade humana e o consequencialismo: a eficiência como parâmetro para decisões judiciais}

O exercício da liberdade é uma função das oportunidades que o indivíduo detém para a realização de escolhas que lhe garantam o bem-estar. Daí a necessidade de garantia da igualdade material para assegurar o exercício da liberdade. Em sociedades que não postulam a igualdade como fundamento de sua constituição, assume-se o risco de não promover a liberdade, mediante a redução de oportunidades.

Ou seja, se uma sociedade vislumbrar desequilíbrio de oportunidades e não promover

envolve normalmente uma avaliação dos custos, riscos e passivos da sociedade (due diligence) pela própria empresa adquirente, o que, não se isenta o alienante do seu dever de informação, reduz evidentemente a sua intensidade." (TEPEDINO, Gustavo; SCHREIBER, Anderson. "Os efeitos da constituição em relação à cláusula da boa-fé no Código de Defesa do Consumidor e no Código Civil". Revista da EMERJ, v. 6, n. 23, 2003.)

${ }^{3}$ Vide BRASIL. CÓDIGO CIVIL. Art. 421. A liberdade contratual será exercida nos limites da função social do contrato. 
meios de estímulo à sua composição, assumem-se os riscos de dano, decorrentes de transações altamente desproporcionais em termos de custo e utilidade sociais. A não inserção de pessoas com deficiência e de aprendizes no mercado de trabalho são exemplos de redução de oportunidades, bem como políticas de redução de acidentes de trabalho em relação à geração de custos sociais desproporcionais.

A questão é que a tomada de decisões pelos indivíduos, que visam maximizar o alcance de bens, passa por uma análise de custo-benefício, por meio do estudo das consequências da aplicação de normas jurídicas. Assim, a força motriz da tomada da decisão individual ou de um grupo é gerada mais pela probabilidade dos efeitos (consequências) do que pelas causas.

Torna-se imprescindível, portanto, analisar as consequências das ações. Essa visão pode, de plano, parecer uma relativização dos bens jurídicos "vida" e "dignidade" como valor e fundamento, respectivamente, essenciais para a convivência humana. Contudo, a análise das consequências parte dos impactos decorrentes de violações a direitos nas relações de trabalho, com destaque na eficiência da proteção a saúde e segurança do trabalhador.

A Organização Internacional do Trabalho - OIT (2021) declara que, conforme suas estatísticas, a cada 15 segundos, morre um trabalhador em virtude de um acidente de trabalho ou de doença relacionada à atividade laboral, o que resulta em 6.300 mortes por dia. Por ano, ainda aponta a OIT, 313 milhões de trabalhadores e trabalhadoras sofrem lesões profissionais não fatais, ou seja, 860.000 pessoas feridas no trabalho todos os dias.

Estima-se que, só no Brasil, a cada minuto, um trabalhador é vítima de acidente de trabalho. Em 2019, foram identificados 582.507 acidentes de trabalho com comunicação de acidente de trabalho (CAT) registrada (BRASIL, 2019). Logo, esses dados não refletem o real cenário, já que não contemplam os subnotificados.

Em relação apenas aos trabalhadores formais, entre os anos de 2012 a 2018, o DIESAT (Departamento Intersindical de Estudos e Pesquisas de Saúde e dos Ambientes de Trabalho) aponta, com base nos dados do Observatório Digital de Segurança e Saúde do Trabalho, do Ministério Público do Trabalho, que máquinas e equipamentos causaram 2.058 mortes - praticamente uma morte por dia de trabalhadores no Brasil -, e também 25.790 amputações causadas por máquinas (DIESAT, 2020).

A OIT (2021) entende "que a única forma eficaz de fazer face a novos e antigos riscos passa pelo enquadramento dos dispositivos legais e das atividades numa forte cultura de 
segurança”".

Cabe, então, questionar por que as leis de proteção à saúde e segurança do trabalho não estimulam condutas que revertam índices desastrosos.

No caso dos custos suportados pelo INSS em casos de doenças e acidentes decorrentes da atividade laboral, a sociedade arca com a responsabilidade de danos decorrentes da exploração de mão de obra para a realização de atividade econômica em benefício de uma empresa ${ }^{4}$. Em uma análise jurídico-econômica, constata-se que a eficiência não é alcançada, dados os altos custos sociais, contrapondo-se aos propósitos constitucionais (garantia de vida e dignidade). De acordo com o art. 170 da Constituição Federal, a livre iniciativa deve ser exercida nos limites em que esteja assegurado o valor social do trabalho, visando à construção de uma sociedade verdadeiramente livre, justa e solidária, objetivos fundamentais da República brasileira (art. $3^{\circ}-$ I, da CF/88).

Contudo, o poder de mercado dita suas regras, ao ponto de se postular que a lógica dos resultados dificulta a aplicação de princípios éticos (SALOMÃO FILHO, 2009, p. 28). Como aplicar os princípios éticos, mas também jurídicos, como garantia à vida e à dignidade nesse contexto?

Inicialmente, e sem abandonar uma proposta humanista, o retorno à ética da vida digna depende, juridicamente, de estímulos de condutas, a partir de um sistema de responsabilidade a ser reconhecido pelo ordenamento jurídico. A ideia de responsabilidade jurídica conduz a uma ótica de transação: se um indivíduo decide pelo exercício da sua liberdade (autonomia da vontade) e realiza uma conduta que envolve a sociedade, ele assume previamente o custo de sua ação. Nesses termos, Richard A. Posner (2007, p. 480) lembra que pode parecer artificial falar sobre acidente como transação, mas ele examina a transação potencial que consiste em comprar a medida de segurança que teria, no exemplo por ele citado, evitado o acidente:

Tendo em vista que uma vítima potencial não pagaria $\$ 3$ para evitar um custo esperado de acidente de $\$ 1$, seu preço ofertado será inferior ao preço solicitado do causador potencial do dano, e a transação não será maximizadora de riqueza. Porém, se esses números forem invertidos - se um custo esperado de acidente de $\$ 3$ pudesse ser evitado a um custo de $\$ 1$-, a

\footnotetext{
${ }^{4}$ Nos termos do artigo $2^{\circ}$, caput, da CLT, empregador é "a empresa, individual ou coletiva, que, assumindo os riscos da atividade econômica, admite, assalaria e dirige a prestação pessoal de serviço".
} 
transação seria maximizadora de riqueza.

O Supremo Tribunal Federal (2021), no dia 12 de março de 2020, aprovou tese para fins de repercussão geral (Tema 932), segundo a qual se reconhece a compatibilidade do artigo 927, parágrafo único, do Código Civil com o artigo $7^{\circ}$, XXVIII, da Constituição Federal,

sendo constitucional a responsabilização objetiva do empregador por danos decorrentes de acidentes de trabalho, nos casos especificados em lei, ou quando a atividade normalmente desenvolvida, por sua natureza, apresentar exposição habitual a risco especial, com potencialidade lesiva e implicar ao trabalhador ônus maior do que aos demais membros da coletividade. que garante ao trabalhador que atua em atividade de risco o direito a indenização em razão de danos decorrentes de acidente de trabalho, independentemente da comprovação de culpa ou dolo do empregador.

Dessa forma, se um empregador decide pelo exercício da sua livre iniciativa (autonomia da vontade) explorar a mão de obra sem a adoção dos devidos cuidados referentes à saúde e à segurança do trabalhador, assume previamente o risco de causar danos e os custos de sua ação, independentemente de sua intenção. Ou seja, trata-se de uma ótica consequencialista: se a causa for reduzir custo da atividade econômica ou desconhecimento das externalidades negativas, as consequências jurídicas (violação ao direito à vida e à dignidade) e econômicas são por ele suportadas. A livre iniciativa demanda responsabilidade pela análise das consequências da atividade econômica explorada, incluindo os impactos com a utilização de mão de obra.

Logo, considera-se tanto a importância da análise dos custos (consequências de uma decisão/conduta) em uma sociedade capitalista, quanto as consequências envolvendo outros fatores (jurídicos, sociais) que devem ser avaliadas, com destaque aqui para as que envolvem as relações de trabalho. As normas jurídicas, sob essa perspectiva, estabelecem uma lógica de maximização de resultados de promoção de valores jurídicos, e também econômicos, com busca do maior ganho com menos recursos, minimizando os custos sob uma perspectiva global. Ao proteger o direito à vida e à dignidade do trabalhador, por meio de um sistema de responsabilidade jurídica, promove-se a igualdade material do trabalhador, na relação de trabalho. 


\section{CONSIDERAÇÕES FINAIS}

As normas jurídicas, com destaque para as que definem o sistema de responsabilidade jurídica, visam a evitar quadros de ineficiência, ou seja, conter as falhas decorrentes das relações entre os particulares, como foi analisado nos gastos com a Previdência Social. Observa-se que a opção pela proteção da vida e da saúde do trabalhador é uma decisão maximizadora de "riqueza", isto é, uma escolha que se traduz em consequências constitucional e economicamente almejadas pela sociedade.

Por essas razões, no âmbito das relações de trabalho subordinado, ao Estado atribuise a função de garantir a observância de direitos fundamentais do trabalhador (maximizadoras de valores indispensáveis ao equilíbrio da sociedade). E essa discussão passa por políticas públicas de promoção de igualdade material, seja por meio de ações afirmativas ou ainda por um sistema de responsabilidade jurídica, que estimule condutas de proteção à vida e a dignidade, como postulados constitucionais, mas também éticos.

Portanto, devemos entendemos que o trabalho é direito individual fundamental e não pode haver forma alternativa de exploração do labor fora do alcance do direito do trabalho, de modo que a reorganização atual deve ser devidamente acompanhada e controlada, de acordo com os princípios norteadores desse ramo do direito.

Resta claro que as novas tecnologias e novos modelos econômicos - decorrente da disseminação do uso da internet e da tecnologia de informação - não podem dirimir ou reduzir o direito ao trabalho e a sua efetiva remuneração.

O direito do trabalho deve cumprir sua função de regulador da concorrência em patamares mínimos de dignidade da pessoa humana garantindo a pessoa humana o direito ao trabalho que supra a sua sobrevivência e a de sua família.

Assim o direito do trabalho, como técnica de civilização, deve se amoldar à nova forma em que se apresenta, ou seja, adaptar-se a faceta da organização da força de trabalho mesmo que modificada a fim de proteger a dignidade do trabalhador.

\section{REFERÊNCIAS}

ARAÚJO, Luiz Alberto David. A proteção constitucional das pessoas portadoras de deficiência. 2. ed. Brasília: Corde, 1996. 
AQUINO, Juliana Maria et al. "Trabalho infantil: persistência intergeracional e decomposição da incidência entre 1992 e 2004 no Brasil rural e urbano”. Rev. econ. contemp., Rio de Janeiro, v. 14, n. 1, 2010, p. 61-84. Disponível em https://www.scielo.br/j/rec/a/tGT7VnBQC8RtJqVqKq4kWLN/?lang=pt Acesso em 20 abr. 2021

ARENDT, Hannah. A condição humana. Rio de Janeiro: Forense Universitária, 1981.

ARRUDA, Kátia Magalhães. Direito constitucional do trabalho. São Paulo: LTr, 1998.

BASTOS, Celso Ribeiro \& MARTINS, Ives Gandra. Comentários à Constituição do Brasil Promulgada em 5 de outubro de 1998. II v., art. 5.o a 17, São Paulo, Editora Saraiva, 1988.

BOBBIO, Norberto. A era dos direitos. Rio de Janeiro: Campus, 2004.

BRASIL. Ministério da Economia. Secretaria de Previdência. Dados estatísticos - Saúde e segurança do trabalhador - 2019. Disponível em https://www.gov.br/previdencia/ptbr/assuntos/previdencia-social/saude-e-seguranca-do-trabalhador/dados-de-acidentesdo-trabalho Acesso em 21 abr. 2021.

BRASIL. Supremo Tribunal Federal (Pleno). Adin 939-07/DF. I.P.M.F. Imposto Provisório sobre a Movimentação ou a Transmissão de Valores e de Créditos e Direitos de Natureza Financeira. - I.P.M.F. Recorrente: Confederação Nacional dos Trabalhadores no Comércio. Recorrido: Presidente da República. Relator: Min. Sidney Sanches, 15 de dezembro de 1993. Publ. DJ 18 mar. 1994.

BRITO COSTA, Sandra Morais de. "O dimensionamento dos direitos trabalhistas como direitos fundamentais”. Rev. “O Elo”, São Paulo, n. 252, jul./ago. 2004.

CAMPILONGO, Celso Fernandes. "Os desafios do Judiciário: um enquadramento teórico". In: FARIA, José Eduardo (Org.). Direitos humanos, direitos sociais e justiça. São Paulo: Malheiros, 2005.

CASTEL, Robert. From Manual Workers to Wage Laborers: Transformation of the Social Question. New Brunswick, New Jersey: Transaction Publishers. 2003.

COSTA, M. A.; MARGUTI, B. O. Atlas da vulnerabilidade social nas regiões metropolitanas brasileiras. Brasília: Ipea, 2015.

DIESAT - Departamento Intersindical de Estudos e Pesquisas de Saúde e dos Ambientes de Trabalho Manifesto referente ao trâmite de alterações das normas 
regulamentadoras. 2020. Disponível https://diesat.org.br/2020/04/manifesto-referenteao-tramite-de-alteracoes-das-normas-regulamentadoras/ Acesso em 21 abr. 2021

MARGUTI, Bárbara Oliveira \& SANTOS, Rodrigo Marques dos. Avaliação continuada da vulnerabilidade social no Brasil : impressões e primeiros resultados do Índice de Vulnerabilidade Social (IVS) 2016-2017. In: IPEA. Boletim regional, urbano e ambiental. $\quad$ v. 21. jul.-dez. 2019 Disponível em: http://repositorio.ipea.gov.br/bitstream/11058/9607/1/BRU_n21.pdf. Acesso em 20 abr. 2021

MELO, Luís Antonio Camargo de. et alli. O novo direito do trabalho: A era das cadeias produtivas. Uma análise do Protocolo Adicional e da Recomendação Acessória à Convenção 29 da OIT sobre Trabalho Forçado ou Obrigatório. In: Revista - Direitos, Trabalho e Política Social. Universidade Federal do Mato Grosso. p. 311-335. Disponível https://periodicoscientificos.ufmt.br/ojs/index.php/rdtps/article/view/8751/5958 Acesso em 20 mar. 2021

MELO, Luís Antonio Camargo de. et al. O novo direito do trabalho: A era das cadeias produtivas. Uma análise do Protocolo Adicional e da Recomendação Acessória à Convenção 29 da OIT sobre Trabalho Forçado ou Obrigatório. Revista Direitos, Trabalho e Política Social, jul./dez. 2015. v. 1, n. 1, 2015, p. 311-335. Disponível em https://periodicoscientificos.ufmt.br/ojs/index.php/rdtps/article/view/8751/5958 Acesso em 20 mar. 2021.

MELlO, Celso Antonio Bandeira de. Curso de Direito Administrativo. 12. ed. São Paulo: Malheiros, 2000.

MORAES, Maria Celina Bodin de. Danos à pessoa humana. Rio de Janeiro: Renovar, 2003.

MORAES FILHO, Evaristo de. Temas atuais de trabalho e previdência. São Paulo: LTr, 1975.

RAMOS, Carmem Lúcia Silveira. “A constitucionalização do direito privado e a sociedade sem fronteiras". In: FACHIN, Luiz Edson (coord.). Repensando fundamentos do direito civil brasileiro contemporâneo. Revista da Faculdade de Direito de Campos, ano VII, n. 8 , jun./2006. 
ORGANIZAÇÃO INTERNACIONAL DO TRABALHO. Segurança e saúde no trabalho. Disponível em https://www.ilo.org/lisbon/temas/WCMS 650864/lang--pt/index.htm Acesso em 21 abr. 2021.

ORGANIZAÇÃO INTERNACIONAL DO TRABALHO. Segurança e saúde no trabalho. 2021. Cit. Disponível em https://www.ilo.org/lisbon/temas/WCMS 650864/lang-pt/index.htm. Acesso 21 abr. 2021

POSNER, Richard A. Problemas de filosofia do direito. São Paulo: Martins Fontes, 2007.

SALOMÃO FILHO, Calixto. "Poder econômico: um monstro domesticável ou uma realidade insubmissa”. In. FERRAZ JÚNIOR, Tércio Sampaio et alli. (Org.) Poder econômico Direito, pobreza, violência, corrupção. Barueri: Manole, 2009.

SANTOS, Boaventura Sousa. Globalização e as ciências sociais. São Paulo: Cortez, 2002.

SATARIANO, Adam. Uber Drivers Are Entitled to Worker Benefits, a British Court Rules. The New York Times. New York. 19 fev. 2021. Disponível em https://www.nytimes.com/2021/02/19/business/uber-drivers-britain.html Acesso 21 abr. 2021

SUPREMO TRIBUNAL FEDERAL. Notícias STF - Aprovada tese que garante a trabalhador em atividade de risco direito a indenização em caso de acidente. Disponível http://www.stf.jus.br/portal/cms/verNoticiaDetalhe.asp?idConteudo=439172\&caixaBus $\mathrm{ca}=\mathrm{N}$ Acesso em 21 abr. 2021.

WOLGANG, Ingo. A eficácia dos direitos fundamentais. Porto Alegre: Livraria do Advogado, 2004. 